CAHIER DE RECHERCHE $\sharp 0890 \mathrm{E}$

Département de science économique

Faculté des sciences sociales

Université d'Ottawa
WORKING PAPER \#0809E

Department of Economics

Faculty of Social Sciences

University of Ottawa

\title{
Energy Substitutability in Canadian Manufacturing Econometric Estimation with Bootstrap Confidence Intervals ${ }^{\#}$
}

\author{
Yazid Dissou* and Reza Ghazal**
}

September 2008

\footnotetext{
\# We would like to thank seminar participants at the University of Ottawa, Rizwana Alamgir, Jean-Thomas Bernard, Pierre Brochu, Kathleen Day, David Gray, Bruno Larue, Louis-Philippe Morin, and Serge Nadeau for very helpful comments and discussions. Useful assistance from Meghan Baker, Sean Martineau, and Jennifer Vieno is appreciated. Finally, we acknowledge help from Wulong Gu of Statistics Canada in obtaining Canadian KLEMS data. Usual caveats apply.

${ }^{*}$ Financial support from the IRND fund of the University of Ottawa is acknowledged. Email: ydissou@uottawa.ca.

***Email: rghaz046@uottawa.ca
} 


\begin{abstract}
This study provides estimates of the price and Morishima substitution elasticities between energy and non-energy inputs in two Canadian energy-intensive manufacturing industries: Primary Metal and Cement. The elasticities are estimated using annual industry-level KLEM data (19612003) and relying on two flexible functional forms: the Translog and the Symmetric Generalized McFadden (SGM) cost functions. In addition to the point estimates, the confidence intervals of the elasticities are computed using single- and double-bootstrap resampling techniques. For both industries, the estimation results suggest that capital, labour, material and energy are pairwise substitutes and that energy is the most substitutable input. However, the low magnitudes of the estimated elasticities do not seem to offer great flexibility to these industries to adapt to high increases in energy prices.
\end{abstract}

Keywords: Energy; Elasticity of substitution; Translog cost function; Symmetric Generalized McFadden (SGM) Cost Function; Single Bootstrap; Double Bootstrap.

JEL Classification: C30, Q4.

\title{
Résumé
}

Cette étude fournit des estimations des élasticités prix et des élasticités de substitution de Morishima entre l'énergie et les intrants non énergétiques dans deux industries manufacturières canadiennes qui sont intensives en énergie, que sont l'industrie de fabrication primaire du métal et l'industrie du ciment. Les élasticités sont estimées en utilisant la base de données annuelles KLEM (1961-2003) et en recourant à deux formes fonctionnelles flexibles, que sont les fonctions de coût Translog et la Symmetric Generalized McFadden (SGM). En plus des estimations ponctuelles, les intervalles de confiance des élasticités sont fournis en utilisant les techniques de ré-échantillonnage "bootstrap » de types simple et double. Les résultats d'estimation suggèrent que le capital, le travail, les matériaux et l'énergie sont tous substituts deux à deux et que l'énergie est l'intrant le plus substituable parmi les quatre. Toutefois, les faibles valeurs des élasticités estimées ne semblent pas offrir une grande souplesse à ces deux industries pour s'adapter à de fortes augmentations de prix de l'énergie.

Mots-clé: Énergie; élasticité de substitution; fonction de coût Translog; fonction de coût Symmetric Generalized McFadden; bootstrap simple; double bootstrap.

Classification JEL: C30, Q4. 


\section{Introduction}

This study provides econometric estimates of substitution elasticities between energy and non-energy inputs, as well as their confidence intervals for selected Canadian manufacturing industries. The successive oil crises and the growing awareness of societies and governments about environmental pollution and the depletion of nonrenewable energy resources have led to the sustained interest on the part of economists in the importance of energy. Economists have in particular been interested in the possibilities of substituting capital, labour and other inputs for energy.

The ease of change in input combinations induced by variations in input prices is governed by, among other factors, the curvature of the isoquant, which is measured locally by the elasticity of substitution. If non-energy inputs are substitutes for energy, higher energy prices will induce cost-minimizing firms to decrease energy use to attenuate the increase in production cost and to mitigate the fall in output. It follows that the extent to which energy can be substituted for by other production factors will have significant industrial effects. Information on energy substitutability is thus of paramount importance for, on the one hand, predicting the outcome of any policy or shock that affects energy prices and for, on the other hand, evaluating alternative environmental policies.

While a mere knowledge of the type of substitutability (complement or substitute) between energy and other inputs can be sufficient for some analyses, the precise values of these parameters are required in other kinds of investigation. Indeed, the influential critique of Lucas (1976) with regard to the inadequacy of using traditional econometric models for the purposes of policy evaluation has led to a substantial shift toward the development of structural models to evaluate policy reform proposals and economic shocks. A distinctive feature of these structural models is their strong micro-foundations, whereby the behaviour of private economic agents is explicitly modeled through a detailed specification of preferences and technologies.

Computable general equilibrium (CGE) models, which constitute a particular type of structural model, have now become an important tool for analyzing policy shocks related to the energy sector. These models have been widely employed to analyze energy policies in different regions of the world. ${ }^{1}$ They rely heavily on the values of substitution elasticities between pairs of inputs to characterize firm technology. Yet, the values of these critical parameters are not estimated within these models; they are rather taken from other studies. Given the sectoral nature of these models, the number of required elasticities is large and reliable estimates do not

\footnotetext{
${ }^{1}$ See Bhattacharyya (1996) and Devarajan and Robinson (2005) for surveys.
} 
always exist for the economy and sectors under study. CGE modellers are often compelled to borrow from a handful of estimates available in the literature to calibrate their models. The paucity of econometric estimates of elasticities used in CGE models has led some authors to question their empirical foundations (see Hansen and Heckman, 1996 and McKitrick, 1998.)

Several attempts were made in the past few decades to estimate the elasticities of substitution between energy and other inputs for various industries in different regions of the world. Studies by Berndt and Wood (1975), Berndt and Jorgenson (1973) for the U.S. economy and by Fuss (1977) for the Canadian economy are milestones in this area. Despite the significant number of studies, there is still no clear consensus over the signs and the magnitudes of these parameters. ${ }^{2}$ Econometric estimates suggest both complementarity and substitutability between energy and non-energy inputs. Results from Berndt and Wood (1975), and Griffin and Gregory (1976) on the U.S. economy are often contrasted in the literature to illustrate how much estimates of the elasticity of substitution between energy and other factors can vary. Berndt and Wood (1975) find that energy is a substitute for capital but a complement of labour, while Griffin and Gregory (1976) find that energy is a substitute for both capital and labour. More recently, Denny et al. (1978) find that energy is a complement to capital in Canadian manufacturing industries, while results in Gervais et al. (2008) suggest that capital and energy are substitutes in the Canadian Food industry. The importance of these differences in the nature of substitutability between energy and capital, for example, cannot be ignored as they have different implications, as far as energy policy is concerned.

The objective of this study is to contribute to this literature by providing econometric estimates of the substitution and price elasticities between energy and the other production factors in some Canadian manufacturing industries. Additional recent estimates of elasticities of substitution between energy and other inputs are much needed in Canada, an energy-exporting country, as well as a traditional manufacturing-goods exporter, where a heated policy debate is still ongoing over the appropriate energy policy to address climate change. In contrast to other studies that use traditional functional forms like the CES (constant elasticity of substitution) function, our econometric estimation relies on flexible cost functions that have the advantage of not imposing any prior restrictions on the values of the elasticities (Diewert, 1971.) Because econometric estimates of elasticities can vary with the functional form used, we opt to use two well-known cost functions: the Translog cost function and the symmetric generalized McFadden (SGM) cost function. An increasing number of studies are now using the SGM cost function to evaluate the characteristics of firm technology. Kumbhakar (1994), Lawrence (1989),

\footnotetext{
2 Thompson and Taylor (1995) and Thompson (2006) survey the empirical studies on this subject.
} 
Peters and Surry (2000), Rask (1995), Sauer (2006), and Stewart and Jones (2008) are few examples, among many others.

While the Translog cost function is the most popular among the functional forms, it does not necessarily respect globally the theoretical curvature properties that a well-behaved cost function should have. Diewert and Wales (1987) show that these properties cannot be imposed globally without destroying the flexibility properties of the cost function. They propose the SGM cost function, which does not have that deficiency; this functional form is now considered the state-of-the-art specification in the analysis of firm technology because of its theoretical consistency.

Another methodological issue addressed in this study pertains to the confidence intervals for substitution elasticities. Most general equilibrium models used for the evaluation of energy policies are not stochastic; they rely on sensitivity analyses of the extraneous elasticity parameters they use to check the robustness of their results. The theoretical distribution of the elasticity parameters obtained using flexible forms are often not known, since they are nonlinear combinations of estimated parameters obtained from regression analyses. In this study, in addition to obtaining point estimates of the elasticities, we provide confidence intervals of these parameters by relying on the resampling bootstrap technique that is more appropriate for constructing confidence intervals when the distribution of the statistics is not known (Eakin et al., 1990). In particular, we use the double bootstrap method that reportedly produces more reliable confidence intervals than the single bootstrap technique. The results of this study will be useful for Canadian CGE modellers, providing them with appropriate information to perform sensitivity analyses of their findings to parameter uncertainty. We are not aware of any study on energy substitutability with an SGM specification that provides bootstrap confidence intervals.

The remainder of the paper is organised as follows. The next section presents the specification of the models that we employ and their econometric estimation strategy; the third discusses the data and the results and the last section concludes.

\section{The model}

We suppose the existence at the industry level of a twice-continuously differentiable production function that combines capital $(K)$, labour $(L)$, energy $(E)$ and material $(M)$ to produce a single gross output $(Y){ }^{3}$ A theoretical representation of the production of gross output that allows for non-neutral technical change can be stated as follows:

$Y=f(K, L, E, M, t)$

${ }^{3}$ For the sake of notational simplicity, industry and time subscripts are omitted. 
where $f$ is a twice continuously differentiable production function and $t$ is an index of technical progress represented by the time trend. We suppose that the technology is homothetic and is characterized in particular by constant returns to scale.

Using duality theory, the technology can be represented by a twice-continuously differentiable cost function that has input prices $\left(w_{j}\right)$, gross output $(Y)$ and the time trend $(t)$ as arguments. The cost function is the solution to the following problem:

$C=C(W, Y, t)=\min _{X}\left\{W^{\prime} X: f(X, t) \geq Y, \quad X>0\right\}$

where $W$ is the vector of input prices and $X$ is the vector of input quantities.

This cost function summarizes all relevant characteristics of the underlying technology if it is linear homogeneous and non-decreasing in prices, concave in prices and nonnegative. It can be represented by a flexible functional form, which is considered an approximation of the true unknown cost function. The flexibility property of these functions stems from the fact that they have a sufficient number of parameters to approximate an arbitrary twice-continuously differentiable function. More precisely, a functional form is considered flexible if its shape is only restricted by theoretical considerations, i.e., the regularity properties (Diewert, 1971). The use of flexible functional forms to estimate technology parameters is appealing since, in contrast to traditional functional forms like CES (Constant Elasticity of Substitution) and C-D (Cobb-Douglas), they do not impose a priori restrictions on elasticity values.

While several flexible functional forms have been proposed in the literature to represent well-behaved cost functions, we consider two functional forms: the Translog cost function (TCF) suggested by Christensen, Jorgenson and Lau (1971, 1973) and the SGM cost function. The TCF is very popular among economists as it stands to be the most widely used second order flexible functional form that can assess the behavioural characteristics of firm technologies. ${ }^{4}$

The property of concavity in prices that any well-behaved cost function must respect cannot be imposed during estimation of the TCF without destroying its flexibility properties. Several studies have reported that estimated TCFs fail to satisfy that property globally. ${ }^{5}$ The concavity property of a cost function is very important for at least two reasons. First, when the cost function is not concave in prices, the input demand determined through the first-order conditions might not be the costminimizing one. Second, the absence of concavity could lead to a non-continuous input demand function. Yet, from a general equilibrium perspective, the continuity of the excess demand function is critical for the existence of Walrasian equilibrium.

${ }^{4}$ See Apostolakis (1990) and Thompson and Taylor (1995) for some interesting reviews of studies using the TCF.

${ }^{5}$ See for example Ryan and Wales (2000). 
To address the deficiencies of the TCF, we use another functional form, the SGM. As discussed in Diewert and Wales (1987), the parameters of the latter function can be estimated while globally imposing concavity in input prices without destroying its flexibility properties.

\subsection{The Translog cost function}

Letting $C$ denote total expenditures on inputs, the TCF can be represented as follows: ${ }^{6}$

$$
\begin{aligned}
\ln C & =\beta_{0}+\sum_{i} \beta_{i} \ln w_{i}+\beta_{y} \ln Y+\beta_{t} t+\frac{1}{2} \sum_{i} \beta_{i i}\left(\ln w_{i}\right)^{2} \\
& +\frac{1}{2} \sum_{i \neq j} \sum_{j} \beta_{i j} \ln w_{i} \ln w_{j}+\sum_{i} \beta_{i t} t \ln w_{i} \quad i, j=K, L, E, M
\end{aligned}
$$

where $\beta_{0}, \beta_{i}, \beta_{y}, \beta_{i j}$ and $\beta_{i t}$ are parameters to be estimated. Imposing linear homogeneity and symmetry restrictions implies the following relationships between the parameters:

$$
\sum_{i} \beta_{i}=1, \quad \sum_{j} \beta_{i j}=0, \quad \sum_{i} \beta_{i t}=0, \quad \beta_{i j}=\beta_{j i} .
$$

Using Shephard's lemma, the share, $S_{i}$, of input $i$ in total cost is:

$$
\begin{aligned}
& S_{i}=\beta_{i}+\beta_{i i} \ln w_{i}+\sum_{j \neq i} \beta_{i j} \ln w_{j}+\beta_{i t} t \\
& i, j=K, L, E, M
\end{aligned}
$$

As the sum of the input shares must be equal to one (adding-up property), the following restriction, which already holds through the linear homogeneity restriction, must be satisfied: $\sum_{i} \beta_{i}=1$.

The econometric approach used consists of adding a random term $u_{i}$ to each share equation and in estimating the parameters of three of the four share equations while imposing the above-mentioned restrictions. The error terms $u_{i}$ are assumed to have zero mean and constant variance, but they are contemporaneously correlated across equations. The equation for material inputs is removed from the econometric estimation to avoid singularity because of the adding-up property. The parameters of the last equation are recovered using the linear homogeneity and symmetry restrictions.

\footnotetext{
${ }^{6}$ For notational simplicity, we ignore the industry subscript in our notation.
} 


$$
\begin{aligned}
& S_{K}=\beta_{K}+\beta_{K K} \ln \left[\frac{w_{K}}{w_{M}}\right]+\beta_{K L} \ln \left[\frac{w_{L}}{w_{M}}\right]+\beta_{K E} \ln \left[\frac{w_{E}}{w_{M}}\right]+\beta_{K t} t+u_{K} \\
& S_{L}=\beta_{L}+\beta_{K L} \ln \left[\frac{w_{K}}{w_{M}}\right]+\beta_{L L} \ln \left[\frac{w_{L}}{w_{M}}\right]+\beta_{L E} \ln \left[\frac{w_{E}}{w_{M}}\right]+\beta_{L t} t+u_{L} \\
& S_{E}=\beta_{E}+\beta_{K E} \ln \left[\frac{w_{K}}{w_{M}}\right]+\beta_{L E} \ln \left[\frac{w_{L}}{w_{M}}\right]+\beta_{E E} \ln \left[\frac{w_{E}}{w_{M}}\right]+\beta_{E t} t+u_{E}
\end{aligned}
$$

Using the estimated parameters and the fitted values of the input shares, the Allen partial elasticities of substitution (AES), $\hat{\sigma}_{i j}^{A}$, could be estimated as follows.

$$
\begin{aligned}
\hat{\sigma}_{i j}^{A} & =\frac{\hat{\beta}_{i j}+\hat{S}_{i} \hat{S}_{j}}{\hat{S}_{i} \hat{S}_{j}} \text { for } i \neq j \\
\hat{\sigma}_{i i}^{A} & =\frac{\hat{\beta}_{i i}+\hat{S}_{i}^{2}-\hat{S}_{i}}{\hat{S}_{i}^{2}}
\end{aligned}
$$

$i, j=K, L, E, M$

Positive values for these elasticities suggest that the inputs are substitutes, while negative values suggest that they are complements. Estimates of cross-price elasticities, $\hat{\varepsilon}_{i j}$, are obtained from estimates of the Allen partial elasticities of substitution and of the fitted values of the input shares expressed below:

$$
\hat{\varepsilon}_{i j}=\hat{S}_{j} \hat{\sigma}_{i j}^{A} \quad i, j=K, L, E, M
$$

While the partial elasticity of substitution is widely used to classify pairs of inputs as substitutes or complements, Blackorby and Russell (1989) criticize its use for this purpose. They argue that the AES cannot be considered as an indicator of ease of substitution in the spirit of the marginal rate of substitution. Rather, they suggest using the Morishima elasticity of substitution (MES), $\hat{\sigma}_{i j}^{M}$, which truly reflects the characteristics of the Hicksian notion of elasticity of substitution for the case of two inputs. They show that the MES is a natural generalization of the Hicks concept of elasticity of substitution in the case of more than two inputs. The MES indicates the percentage change in proportional factor inputs that is brought about by a change in relative prices, while keeping output and all prices but one constant. Its expression is: 


$$
\hat{\sigma}_{i j}^{M}=\varepsilon_{i j}-\varepsilon_{j j}
$$

However, in contrast to the AES, the MES is not symmetric. Moreover, the Morishima measure tends to treat inputs as substitutes, while the AES tends to treat them as complements. If two inputs are Allen substitutes, it must be the case that they are Morishima substitutes; however, the converse is not true. In this study, we report only estimates of the MES.

\subsection{The symmetric generalized McFadden cost function (SGM)}

The linear homogeneous and homothetic version of the SGM cost function initially proposed is defined as follows:

$C(Y, W)=\left(g(W)+\sum_{i} b_{i i} w_{i}+b_{i t} w_{i} t\right) Y$

with $g(W) \equiv \frac{W^{\prime} S W}{2 \theta^{\prime} W}$

$i, j=K, L, E, M$

where $S$ is a $4 \times 4$ symmetric negative semi-definite matrix of parameters $s_{i j}$ and $\theta(\theta>0)$ is a $4 \times 1$ vector of nonnegative constants that are not all equal to zero and that can be freely chosen by the researcher. As in Diewert and Wales (1987), we set the elements of the vector $\theta$ equal to the sample average values of the inputs. The parameters $b_{i i}$ and $b_{i t}$ along and $s_{i j}$ are the parameters to be estimated.

Some additional restrictions are required in order to identify all parameters. As suggested by the authors of this functional form, the following restriction can be imposed at some chosen input prices $w^{*}\left(w^{*}>0\right): \sum_{j} s_{i j} w^{*}=0$. When the chosen input prices are set equal to one, the preceding restriction can be written as $\sum_{j} s_{i j}=0$. In other words, all rows of the $S$ matrix must sum up to zero. With this in perspective, we rescale all prices so that the input prices of the first year are equal to one.

By differentiating the cost function with respect to input prices, and using Shephard's lemma, it is possible to obtain the conditional factor demands. Dividing each factor demand by the level of output to reduce potential heteroskedasticity, we have the following expressions for the system of input demands:

$$
\frac{X_{i}}{Y}=\frac{\sum_{j} s_{i j} w_{j}}{\theta^{\prime} W}-\frac{\theta_{i}}{2} \frac{W^{\prime} S W}{\left(\theta^{\prime} W\right)^{2}}+b_{i i}+t b_{i t} \quad i=K, L, E, M
$$


When the identification restriction is imposed on the matrix $S$, the input demand system becomes:

$$
\begin{aligned}
& \frac{X_{K}}{Y}=s_{K K}\left[\left(P_{K}-P_{M}\right)-\frac{\theta_{K}}{2}\left(P_{K}-P_{M}\right)^{2}\right]+s_{K L}\left[\left(P_{L}-P_{M}\right)-\theta_{K}\left(P_{K}-P_{M}\right)\left(P_{L}-P_{M}\right)\right] \\
& +S_{K E}\left[\left(P_{E}-P_{M}\right)-\theta_{K}\left(P_{K}-P_{M}\right)\left(P_{E}-P_{M}\right)\right]+s_{L L}\left[-\frac{\theta_{K}}{2}\left(P_{L}-P_{M}\right)^{2}\right] \\
& +s_{L E}\left[-\theta_{K}\left(P_{L}-P_{M}\right)\left(P_{E}-P_{M}\right)\right]+s_{E E}\left[-\frac{\theta_{K}}{2}\left(P_{E}-P_{M}\right)^{2}\right] \\
& +b_{K K}+t b_{K t}+u_{K} \\
& \frac{X_{L}}{Y}=s_{K K}\left[-\frac{\theta_{L}}{2}\left(P_{K}-P_{M}\right)^{2}\right]+s_{K L}\left[\left(P_{K}-P_{M}\right)-\theta_{L}\left(P_{K}-P_{M}\right)\left(P_{L}-P_{M}\right)\right] \\
& +s_{K E}\left[-\theta_{L}\left(P_{K}-P_{M}\right)\left(P_{E}-P_{M}\right)\right]+s_{L L}\left[\left(P_{L}-P_{M}\right)-\frac{\theta_{L}}{2}\left(P_{L}-P_{M}\right)^{2}\right] \\
& +s_{L E}\left[\left(P_{E}-P_{M}\right)-\theta_{L}\left(P_{E}-P_{M}\right)\left(P_{L}-P_{M}\right)\right]+s_{E E}\left[-\frac{\theta_{L}}{2}\left(P_{E}-P_{M}\right)^{2}\right] \\
& +b_{L}+t b_{L t}+u_{L} \\
& \frac{X_{E}}{Y}=s_{K K}\left[-\frac{\theta_{E}}{2}\left(P_{K}-P_{M}\right)^{2}\right]+s_{K L}\left[-\theta_{E}\left(P_{K}-P_{M}\right)\left(P_{L}-P_{M}\right)\right] \\
& +s_{K E}\left[\left(P_{K}-P_{M}\right)-\theta_{E}\left(P_{K}-P_{M}\right)\left(P_{E}-P_{M}\right)\right]+s_{L L}\left[-\frac{\theta_{E}}{2}\left(P_{L}-P_{M}\right)^{2}\right] \\
& +s_{L E}\left[\left(P_{L}-P_{M}\right)-\theta_{E}\left(P_{L}-P_{M}\right)\left(P_{E}-P_{M}\right)\right]+s_{E E}\left[\left(P_{E}-P_{M}\right)-\frac{\theta_{E}}{2}\left(P_{E}-P_{M}\right)^{2}\right] \\
& +b_{E E}+t b_{E t}+u_{E} \\
& \frac{X_{M}}{Y}=s_{K K}\left[-\left(P_{K}-P_{M}\right)-\frac{\theta_{M}}{2}\left(P_{K}-P_{M}\right)^{2}\right]+s_{K L}\left[-\left(P_{L}-P_{M}\right)-\theta_{M}\left(P_{K}-P_{M}\right)\left(P_{L}-P_{M}\right)\right] \\
& +s_{K E}\left[-\left(P_{E}-P_{M}\right)-\theta_{M}\left(P_{K}-P_{M}\right)\left(P_{E}-P_{M}\right)\right]+s_{L L}\left[-\left(P_{L}-P_{M}\right)-\frac{\theta_{M}}{2}\left(P_{L}-P_{M}\right)^{2}\right] \\
& +S_{L E}\left[-\left(P_{L}-P_{M}\right)-\left(P_{E}-P_{M}\right)-\theta_{M}\left(P_{L}-P_{M}\right)\left(P_{E}-P_{M}\right)\right] \\
& +S_{E E}\left[-\left(P_{E}-P_{M}\right)-\frac{\theta_{M}}{2}\left(P_{E}-P_{M}\right)^{2}\right]+b_{M M}+t b_{M t}+u_{M}
\end{aligned}
$$


where the $u_{i}$ are the error terms and the independent variables $P_{i}$ are the normalized input prices such that: $P_{i}=\frac{w_{i}}{\sum_{j} \theta_{j} w_{j}}(i, j=K, L, E, M)$. Recall that the parameters to be estimated are $s_{i p}, b_{i i}$ and $b_{i t}$, and note that the expressions in brackets are nonlinear combinations of input prices, which are independent variables. ${ }^{7}$ One can easily see that the demand system is linear in parameters. It is also worth mentioning that the parameters $s_{i M}(i=K, L, E, M)$ do not appear in the list of estimated parameters because of the identification restriction we have imposed. Their values can be recovered by using those estimated directly from the system while taking into consideration the identification restriction.

If the estimated matrix, $\hat{S}$, does not satisfy the concavity criteria, Diewert and Wales (1987) show that it is possible to impose globally negative semi-definiteness without destroying the flexibility property of the cost function. Relying on the method suggested by Wiley et al., (1973), they reparametrize the $S$ matrix through Cholesky decomposition by replacing it with $-A A$, where $A$ is a lower triangular matrix:

$$
\mathrm{A}=\left[a_{i j}\right] i, j=K, L, E, M \quad a_{i j}=0 \quad \text { for } i<j
$$

The following relationships can then be established between the parameters $s_{i j}$ and $a_{i j}$ :

$S_{K K}=-a_{k k}^{2}$

$s_{K L}=-a_{K K} a_{K L}$

$s_{K E}=-a_{K K} a_{K E}$

$s_{L L}=-\left(a_{K L}^{2}+a_{L L}^{2}\right)$

$s_{L E}=-\left(a_{K L} a_{K E}+a_{L L} a_{L E}\right)$

$s_{E E}=-\left(a_{K E}^{2}+a_{L E}^{2}+a_{E E}^{2}\right)$

As a result, replacing the parameters $s_{i j}$ in the system of equations $(11 \mathrm{a}-\mathrm{d})$ by the expressions $(12 \mathrm{a}-\mathrm{f})$ and estimating the parameters $a_{i j}$ will ensure that the estimated cost function is globally concave. Still, a consequence of this is that the system is no longer linear in the parameters $a_{i j}$. Finally, the own- and cross-price elasticities between inputs in the SGM cost function have the following expressions:

\footnotetext{
${ }^{7}$ Note that with the SGM specification, all four equations are used for estimation.
} 


$$
\begin{aligned}
& \hat{\varepsilon}_{i i}=\left[\frac{\hat{s}_{i i} \sum_{u} \theta_{u} w_{u}-2 \theta_{i} \sum_{u} \hat{s}_{i u} w_{u}+2 \theta_{i}^{2} \hat{g}(W)}{\left[\sum_{u} \theta_{u} w_{u}\right]^{2}}\right] \frac{w_{i} Y}{X_{i}} \\
& \hat{\varepsilon}_{i j}=\left[\frac{\hat{s}_{i j} \sum_{u} \theta_{u} w_{u}-\theta_{i} \sum_{u} \hat{s}_{j u} w_{u}-\theta_{j} \sum_{u} \hat{s}_{i u} w_{u}+2 \theta_{i} \theta_{j} \hat{g}(W)}{\left[\sum_{u} \theta_{u} w_{u}\right]^{2}}\right] \frac{w_{j} Y}{X_{i}}
\end{aligned}
$$

The Morishima elasticities can be computed from the price elasticities using (8b).

\subsection{Confidence intervals with double bootstrap}

As previously stated, the elasticities of interest are not directly estimated from the econometric models. Rather, they are nonlinear functions of estimated coefficients and of fitted values of input cost shares. As a result, the analytical derivation of their confidence intervals is non-tractable as their theoretical distributions are complex. The reason for this is that a nonlinear combination of normally distributed random variables is not necessarily normally distributed. Furthermore, even when the asymptotic distribution of an estimated parameter is well known, the confidence interval built on this distribution can be misleading in small samples.

Using the technique suggested in Efron (1982), Efron and Tibshirani (1993) show that the simple bootstrap method can produce reliable confidence intervals even when the distribution is not known. An increasing body of literature seems to suggest that bootstrap techniques provide better inferences than traditional asymptotic tests, especially in small samples. Horowitz (1994) and Davidson and MacKinnon (1999) are a few examples among others. The single bootstrap technique has been used by several authors to provide confidence intervals for parameters that are nonlinear functions of estimated coefficients from econometric models (see Eakin et al., 1990, Hall and Horowitz, 1996, and Li and Maddala, 1999, among several others, for interesting examples.)

Still, as noted by Leston and McCullough (1998), a major drawback of the single bootstrap method is its slow rate of convergence, whereby the coverage error decreases slowly as the sample size increases. ${ }^{8}$ Some studies show that applying the double bootstrap resampling technique (originally introduced by Beran, 1988) by performing a pivotal transformation", makes it possible to improve the accuracy of the confidence interval obtained using the single bootstrap technique. Confidence intervals obtained using bootstrap techniques based on a pivotal transformation have

\footnotetext{
8 The coverage error of an interval is the difference between its nominal coverage and its actual coverage. The nominal coverage is defined as the proportion of times that the estimated interval covers the true parameter (McCullough and Vinod, 1998).

${ }^{9}$ A pivotal statistic is one whose distribution function does not depend on any unknown parameter. See Davidson and MacKinnon (2002) for some interesting discussions on the double bootstrap technique.
} 
a faster rate of convergence. However, substitution elasticities, which are nonlinear combinations of estimated parameters, do not have stable pivots.

This situation prevents the use of traditional double bootstrap techniques that require a stable pivot. We elect to use Shi (1998)'s double bootstrap method that does not have such a requirement and that has been proven to produce more reliable confidence intervals than the single bootstrap technique. We follow the double bootstrap procedure described in the excellent presentation of McCullough and Vinod (1998) to construct these intervals. See the Appendix for the procedures to compute the confidence intervals.

\section{Data, results and discussions}

\subsection{Data}

The data set we used is the annual Canadian KLEMS data developed by the "Productivity Program Database of Statistics Canada" for the period 1961-2003 in two 4-digit manufacturing industries that are "Primary metal" NAICS (3310) and "Cement" in the NAICS (3273) - at the L-level of aggregation ${ }^{10}$. These two industries have been chosen mainly because of they are energy-intensive. The KLEMS data set includes information on chained-Fisher quantity indices and price indices for capital, labour, energy, material and service inputs, on the quantity index of output, as well as their nominal values on an annual basis. Capital input is represented by the services provided by the stock of capital instead of the stock of capital itself as used in other studies ${ }^{11}$. In this study, material input is represented by a Fischer-chained index of the material input and services input contained in the original database. For the sake of notational simplicity, we use the expression "material input" to refer to the composite of material and services inputs that we still denote by $M$.

Tables 1 and 2 provide a summary of descriptive statistics for selected variables in both industries during the study period. These statistics include the mean, standard deviation, minimum and maximum values of the price and quantity indices and cost shares of the four inputs. In both industries, material inputs account for, on average, the largest expenditure share in production in both industries (more than $60 \%$ ) while energy has the lowest (less than $8 \%$ ).

\footnotetext{
${ }^{10}$ NAICS: North American Industry Classification System. See Baldwin et al. (2007) for details on the methodology used to produce the data set.

${ }^{11}$ Baldwin and $\mathrm{Gu}(2007)$ explain the estimation methods for capital services.
} 


\subsection{Results and discussions}

All estimation is performed using the SHAZAM econometric package (version 10). ${ }^{12}$ The three factor share equations derived from the Translog specification (Equations $6 \mathrm{a}$ to $6 \mathrm{~b}$ ) are estimated using the iterative seemingly unrelated regression (SUR). The four equations of input-to-output ratios obtained in the SGM specification (Equations 11a to 11d) are estimated with nonlinear iterative SUR techniques using the Davidson-Fletcher-Powell algorithm. The initial values of the coefficients $a_{i j}$ in the nonlinear regression are found using the following strategy. First, we estimate the parameters $s_{i j}$ in the non-restricted (for concavity) system of equations; then we use the relationships between $s_{i j}$ and $a_{i j}$ in the Cholesky factorization to find those initial values. The systems converged from the supplied starting values within 115 iterations in both industries. The same initial values are used in the bootstrap estimations.

Tables 3 to 14 report the estimated coefficients from the regressions and the point estimates of elasticities as well as their confidence intervals for both industries. Estimated parameters derived from flexible functional cost functions do not have any intuitive economic interpretation in the sense that they do not convey any special information on the elasticities in which we are interested. We will rather focus on their statistical significance, instead of their signs and magnitudes. The results in Tables 3 to 6 suggest that most estimated parameters of the cost function are significant at the 5 percent level of significance in both specifications and in both industries. In particular, the time trend coefficient is significant at the 5 percent level. Moreover, the relatively high values obtained for $R^{2}$ in both specifications show that the models fit the data well.

To check for the concavity property of the estimated Translog cost function, we compute the eigenvalues of the estimated Hessian matrix at the middle year of the sample period. They fail to meet the criteria for the matrix to be semi-definite, meaning that the estimated Translog cost function is not concave in prices at the middle year of the sample period.

In contrast, the estimated SGM cost function satisfies the concavity property at each data point, since the estimated $\hat{S}$ matrix is negative semi-definite ${ }^{13}$. Table 6 reports the price elasticities and Morishima elasticities of substitution of the independent variables evaluated at the middle year of the sample period. The empirical estimates obtained using Translog and SGM specifications are in most cases similar, but there are some sharp differences in a few cases.

Regarding the price elasticities in Tables 5 and 6, all estimated own-price elasticities are of the right sign, i.e., negative. Moreover, they are all less than one in

\footnotetext{
${ }^{12}$ All reported elasticities are estimated at the middle year of the sample period. The estimated values for the remaining years are displayed in graphs.

${ }^{13}$ None of its eigenvalues is strictly positive.
} 
absolute value, meaning that the derived demand for these inputs is inelastic in both industries. This is an indication of the potential vulnerability of these industries to an increase in factor prices.

However, energy appears to be the most elastic factor among the four inputs in both industries as it has the highest own price elasticity in absolute terms. These results suggest that both industries have a larger ability to cope with an increase in the price of energy than with the prices of other factors. It is worth noticing that the estimated elasticities from Translog specification are in most cases larger in magnitude than the ones estimated from the SGM model. There is no theoretical justification for this; we conjecture that the failure of the estimated Translog cost function to satisfy the concavity property could be one of the reasons explaining these differences.

The point estimates of the Morishima elasticities of substitution are positive for all pairs of inputs for both specifications. This seems to indicate that most of these inputs are substitutes in both industries. However, the estimates are less than one in both industries and for all pairs of factors. The stark difference between the Translog and SGM estimates of the Morishima elasticity of substitution between capital and material input in the Cement industry is worth mentioning. Table 6 reveals a point estimate of 0.55 with Translog vs. 0.05 with SGM for the elasticity of substitution between capital and material input.

The point estimates of the substitution elasticities between energy and other inputs also deserve some attention. Referring to the SGM specification, the results in Tables 5 and 6 indicate that energy is the most substitutable in the Metal industry since the ratios of other inputs to energy are most sensitive to the change in energy prices. For example, using the results in the SGM specification, the ratio of capital to energy will increase by 0.54 percent if the price of energy increases by one percent. Similarly, a one-percent increase in the price of energy will increase the ratio of labour to energy by 0.54 percent.

Thus, if we abstract from the differences in the point estimates obtained using the two specifications, the figures in Table 6 suggest that capital is substitutable for energy in both industries. It follows that a rise in energy prices would spur investment in physical capital in both industries.

Besides, since the Morishima elasticity is asymmetric, the input whose price change alters the price ratio matters for the change in the ratio of input quantities. Thus, for example focusing on the results for the SGM specification, a one-percent increase in the price of energy would increase the ratio of capital to energy by 0.54 percent in the Metal industry. The same one-percent increase in the price of capital would only induce a 0.17 percent rise in the ratio of energy to capital in the same industry. 
Our result on the substitutability between capital and energy is in line with that obtained by Gervais et al. (2008) who use exclusively the TCF to estimate elasticity of scope in the Canadian food-processing industries for the period 1990-1999. It is however different from those in Denny et al. (1978) who find that energy is a complement to capital in Canadian manufacturing industries. This difference between is probably due to the level of aggregation and to the sample period. Denny et al. (1978) consider data spanning from the period 1947 to 1970 for the entire Canadian manufacturing industry, while we use data from two subsets of the same manufacturing industry for the period 1961 to 2003.

\section{Elasticities over time}

The reported elasticities in Tables 5-14 are calculated at the middle year of the sample period. These elasticities vary over time and the changes are shown in Figures 1 to 4 . In particular, the own-price elasticities of capital, labour and energy increase in absolute value for the Cement industry after 1980, while no clear pattern is evident for Metal industry for that variable. Regarding the elasticity of substitution between factors, they appear in general to be stable. In a few instances, there is a clear upward trend after 1980. This is illustrated by the substitution elasticities between capital and labour, and capital and energy in the Metal industry, and between capital and energy in the Cement industry

\section{Confidence intervals}

Tables 7-14 report the 95 percent single- and double-bootstrap confidence intervals for the price and substitution elasticities. Concerning the own-price elasticities, the reported confidence intervals confirm their negative sign and their small magnitude (less than one in absolute terms) with a 95 percent level of confidence. While the computed confidence intervals of the Morishima elasticities confirm, in general, our initial claim that production factors are pair-wise substitutes in both industries, there are only few instances where the 95 percent confidence intervals span positive and negative values. Still, the results from the two specifications of the cost functions yield mixed results.

Indeed, using the Translog specification, the lower bounds of the confidence intervals of the Morishima elasticities between capital and labour and between energy and material inputs are negative in the Metal industry. However, these lower bounds are positive in the SGM specification. Similarly, the lower bound of the substitution elasticity between capital and material input is negative in the SGM specification in the Metal industry, while it is positive with the Translog specification. Still, in all these mixed cases, the negative lower bounds are very small; they fall within the range of -0.04 and -0.01 . This leads us to infer that, at a $90 \%$ level of confidence, these elasticities are positive. Another observation we would like to make is that, 
while it is reported in other studies ${ }^{14}$ that double-bootstrap confidence intervals can often reverse conclusions reached using single-bootstrap intervals, we only have few occurrences of this in our results. The lower bounds of the single- and doublebootstrap confidence intervals of the Morishima elasticities do not have the same sign in only six cases out of $48(12.5 \%)$. This is true for the Morishima elasticity between capital and material inputs in the Metal industry (Table 8).

The two types of confidence intervals are very close to each other in terms of their length. While the double-bootstrap intervals are typically larger than the single bootstrap interval with the Translog specification, the reverse holds in the SGM specification. The double-bootstrap interval does refine the single-bootstrap interval of the substitution elasticities in the SGM specification. One should mention that the observed similarity in length between the single and double-bootstrap confidence intervals has also been reported in another study on the Canadian food industry by Gervais et al. (2008), who rely on a Translog specification.

\section{Concluding remarks}

In this paper, we have estimated the price and Morishima substitution elasticities between energy and other production factors in two Canadian manufacturing industries, using annual industry-level data (1961-2003). The estimation was based on two second-order flexible functional forms - the Translog and the SGM cost functions. The advantage of the SGM cost function is that concavity can be imposed globally without destroying its flexibility property. While this restriction ensures that the results derived from that specification satisfy economic theory, it introduces nonlinearity in the econometric estimation of the parameters.

In addition to providing the point estimates of these elasticities between pairs of inputs, we have also computed their confidence intervals using single- and doublebootstrap resampling techniques. The reported confidence intervals would be useful for numerical modellers who would like to perform sensitivity analysis of their results to the values of elasticities of substitution. In a significant number of occurrences, the double-bootstrap method has allowed us to refine the intervals obtained using single-bootstrap method in the SGM specification. Furthermore, although the estimated parameters obtained from the Translog specification failed ex-post to be globally concave, the computed elasticities using this functional form are in general qualitatively consistent with the ones obtained using the SGM specification.

The common observation emerging from the point estimates of elasticities of substitution for both industries with each of the two specifications, evaluated at the

${ }^{14}$ See McCullough and Vinod (1998). 
middle year of the sample period, is that all four inputs are pair-wise substitutes. Still, the magnitudes of these point estimates are lower than one. In most cases, the single and double-bootstrap 95\% confidence intervals for these elasticities did not allow us to reject the hypothesis that these elasticities are lower than one. This suggests that substitution elasticities between inputs in these two industries are not as large as the findings from other studies seem to suggest.

Finally, energy seems to be the factor that is the most substitutable in both industries. Our results suggest that the two industries are capable of coping with an increase in the price of energy more than they are with the prices of the other factors. Still, the low magnitude of these elasticities does not seem to offer great flexibility for these industries to adapt to high increases in energy prices.

\section{References}

Apostolakis, Bobby E. (1990), "Energy-Capital Substitutability/Complementarity," Energy Economics, 12, 11, 48-58.

Baldwin, J. R., and W. Gu (2007), "Multifactor Productivity in Canada: An Evaluation of Alternative Methods of Estimating Capital Services," The Canadian Productivity Review, Catalogue no. 15-206-XIE2007009, Ottawa: Statistics Canada.

Baldwin, J. R., W. Gu and B. Yan (2007), "User Guide for Statistics Canada's Annual Multifactor Productivity Program," Research paper, The Canadian Productivity Review, Statistics Canada, Catalogue no. 15-206-XIE - No. 14, Ottawa: Statistics Canada.

Barnett, A. H., R., Keith, and Henry Thompson (1998), "Electricity substitution: some local industrial evidence," Energy Economics 20, 411 - 419.

Berndt, E. R., and D. W. Jorgenson (1973), "Production Structures," Chapter 3 in U.S. Energy Resources and Economic Growth, D. W. Jorgenson and H. S. Houthakker, eds. Washington: Energy Policy Project.

Berndt, E. R. and D. O. Wood (1975), "Technology, Prices, and the Derived Demand for Energy," Review of Economics and Statistics, 57.

Bhattacharyya, S. C. (1996), "Applied General Equilibrium Models for Energy Studies: A Survey," Energy Economics 18, 145-164.

Beran, R. (1988), "Prepivoting Test Statistics: A Bootstrap View of Asymptotic Refinements," Journal of the American Statistical Association, 83, 687-697.

Blackorby, C. and R. R. Russell (1989), "Will the Real Elasticity of Substitution Please Stand Up? A Comparison of the Allen/Uzawa and Morishima Elasticities," American Economic Review 79: 882-888.

Christensen, L.R., Jorgenson, D.W. and L.J. Lau (1971), "Conjugate Duality and the Transcendental Logarithmic Production Function," Econometrica, 39, 255-256.

Christensen, L.R., Jorgenson, D.W. and L. J. Lau (1973), "Transcendental Logarithmic Production Frontiers," Review of Economics and Statistics, 55, 28-45. 
Davidson, R., and J. G. MacKinnon (1999), "The Size Distortion of Bootstrap Tests," Econometric Theory, 15, 361-376.

Davidson, R., and J. G. MacKinnon (2002), "Fast Double Bootstrap Tests of Nonnested Linear Regression Models," Econometric Reviews, 21, 417-427.

Denny, M., J. D. May and C. Pinto (1978), "The Demand for Energy in Canadian Manufacturing: Prologue to an Energy Policy," Canadian Journal of Economics, $11,2,300-313$.

Devarajan, S. and S. Robinson (2005), "The Influence of Computable General Equilibrium Models on Policy," in T. J. Kehoe, T. N. Srinivasan, and J. Whalley (eds.) Frontiers in Applied General Equilibrium Modeling In Honor of Herbert Scarf

Diewert, W. E. (1971), "An Application of the Shephard Duality Theorem: A Generalized Leontief Production Function," Journal of Political Economy 79, 481-507.

Diewert, W. E., and T. J. Wales (1987), "Flexible Functional Forms and Global Curvature Conditions," Econometrica, 55, 43-68.

Eakin, B. K., McMillen, D. P. and M. J. Buono (1990), "Constructing Confidence Intervals Using the Bootstrap: An Application to a Multi-Product Cost Function," The Review of Economics and Statistics, 72, 2, 339-44.

Efron, B. (1982), "The Jackknife, the Bootstrap and Other Resampling Plans, Philadelphia," Society for Industrial and Applied Mathematics.

Efron, B., and R. J. Tibshirani (1993), "An Introduction to the Bootstrap," New York, Chapman and Hall.

Fuss, Melvyn A. (1977), "The Demand for Energy in Canadian Manufacturing : An Example of the Estimation of Production Structures with Many Inputs," Journal of Econometrics, 5, 1, 89-116.

Gervais, J.P., Bonroy, O. and S. Couture (2008), "A Province-level Analysis of Economies of Scale in Canadian Food Processing," forthcoming Agribusiness

Griffin, J. M., and P. R. Gregory (1976), “An Intercountry Translog Model of Energy Substitution Responses," American Economic Review, 66, 845-857.

Hall, P. and J. L. Horowitz (1996), "Bootstrap Critical Values for Tests Based on Generalized-Method-of-Moments Estimators," Econometrica, 64, 4, 891-916

Hansen, L. P. and J. J. Heckman (1996), "The Empirical Foundations of Calibration," The Journal of Economic Perspectives, Vol. 10, 1, 87-104.

Horowitz, J. L. (1994), "Bootstrap-based Critical Values for the Information Matrix Test," Journal of Econometrics, 61, 2, 395-411.

Jacoby, Henry D., Reilly, John M., McFarland, James R., and Sergey Paltsev (2006), "Technology and Technical Change in the MIT EPPA Model," Energy Economics 28, 610-631.

Kemfert, Claudia (1998), "Estimated Substitution Elasticities of a Nested CES Production Function Approach for Germany," Energy Economics 20, 249264. 
Kumbhakar, S.C. (1994), “A Multiproduct Symmetric Generalized McFadden Cost Function," Journal of Productivity Analysis 5, 349\{357.

Lawrence D. (1989), "An Aggregator Model of Canadian Export Supply and Import Demand Responsiveness," The Canadian Journal of Economics 22, 3, 503-521

Letson D. and B. D. McCullough (1998), "Better Confidence Intervals: The Double Bootstrap with No Pivot," American Journal of Agricultural Economics, Vol. 80, No. 3 (Aug., 1998), pp. 552-559

Li, H. and G. S. Maddala (1999), "Bootstrap Variance Estimation of Nonlinear Functions of Parameters: an Application to Long-run Elasticities of Energy Demand," The Review of Economics and Statistics, 1999, 81(4): 728-733.

Lucas, Robert (1976), "Econometric Policy Evaluation: A Critique," Carnegie-Rochester Conference Series on Public Policy 1, 19-46.

McCullough, B. D. and H. D. Vinod (1998), "Implementing the Double Bootstrap," Computational Economics 12, 1, 79-95.

McKitrick, R. R. (1998), "The Econometric Critique of Computable General Equilibrium Modeling: The Role of Functional Forms," Economic Modelling, $15,4,1,543-573$

Peters, L. and Y. Surry (2000), "Incorporating Price-Induced Innovation in a Symmetric Generalised McFadden Cost Function with Several Outputs," Journal of Productivity Analysis, 14, 53-70

Rask, K. (1995), "The Structure of Technology in Brazilian Sugarcane Production, 1975-87," Journal of Applied Econometrics 10, 221-232.

Ryan, D. L. and T.J. Wales (2000), "Imposing Local Concavity in the Translog and Generalized Leontief Cost Functions," Economics Letters 67, 253-260.

Sauer J. (2006), "Economic Theory and Econometric Practice: Parametric Efficiency Analysis," Empirical Economics 31, 4, 1061-1087

Shi, S. G. (1992), "Accurate and Efficient Double Bootstrap Confidence Intervals," Computational Statistics and Data Analysis, 13, 21-32.

Stewart, K. G. and J.C.H. Jones (2008), "Are Sports Teams Multiproduct Firms?," mimeo, Department of Economics, University of Victoria, Victoria, British Columbia, Canada.

Thompson, H. (2006), "The Applied Theory of Energy Substitution in Production," Energy Economics 28, 410-425

Thompson, P. and T. Taylor (1995), "The Capital-Energy Substitutability Debate: A New Look," The Review of Economics and Statistics, Vol. 77, No. 3. pp. 565-569.

Wiley, D.E., Schmidt, W.H. and W.J. Bramble (1973), "Studies of a Class of Covariance Structure Models," Journal of American Statistical Association 68, 317-323. 


\section{Appendix}

Once the parameters of the system of equations are estimated, denote by $\hat{\Omega}$ the vector of elasticities of interest, by $\hat{Q}$ the vector of predicted dependent variables, and by the sample of the rescaled residuals, $\hat{e}$, by the factor $\sqrt{\frac{n}{n-p}}$, where $n$ is the number of observations and $p$ the number of regressors plus one. The rescaling of the residuals is performed to keep the pattern of disturbances across equations.

After rescaling the residuals, we form a new sample of residuals $e^{*}$ by a random uniform draw with replacement of the residual vector $\hat{e}$. Next, we obtain a new bootstrap vector of the dependent variable $\left(Q^{*}\right)$ by adding the re-sampled vector of the residual, e*, to the predicted vector of dependent variables, $\hat{Q} . Q^{*}=\hat{Q}+e^{*}$.

Afterwards, the system of equations is estimated once more with the bootstrap vector $Q^{*}$ as dependent variables to form a bootstrap estimate $\Omega^{*}$ of the elasticities. The procedure is repeated B times to obtain B single-bootstrap estimates of the elasticities $\Omega_{b}{ }^{*}$. For each bootstrap sample, the rescaled residuals, $\mathrm{e}^{* *}$, are computed and added to the vector of predicted variables $\hat{Q}^{*}$ to form a new vector of dependent variables, $Q^{* *}$. The system of equations is subsequently estimated using the vector $Q^{* *}$ as dependent variables to form a bootstrap estimate $\Omega^{* *}$ of the elasticities. The procedure is repeated $C$ times to obtain $B C$ estimates of the elasticities $\Omega * *$.

The statistics $I_{b}=\#\left(\Omega_{B C}^{* *} \leq \Omega_{B C}^{*}\right) / C$ are computed. For each elasticity, \# indicates the number of times the condition in the parenthesis holds. After completing all bootstrapping operations, the statistics $\Omega *$ and $\mathrm{I}_{\mathrm{b}}$ are ordered to form two sets $\Omega_{1}^{*}, \Omega_{2}^{*}, \ldots, \Omega_{B}^{*}$, and $I_{1}, I_{2} \ldots, I_{B}$. The single bootstrap $\alpha-\%$ confidence interval of the elasticity is $\left[\Omega_{(J+1)(1-\alpha)}^{*}, \Omega_{(J+1) \alpha}^{*}\right]$. The double bootstrap alpha- $\%$ confidence interval is $\left[\Omega_{(B+1) \alpha_{L}}^{*} \Omega_{(B+1) \alpha_{U}}^{*}\right]$ with $\alpha_{L}=I_{(B+1)(1-\alpha)}$ and $\alpha_{U}=I_{(B+1) \alpha}$. We use the values of 1999 and 500, for respectively, $B$ and $C$, in our empirical computation of the confidence intervals. 
Table 1: Summary statistics for the Metal industry:1961-2003

\begin{tabular}{lrrrr}
\hline & Mean & $\begin{array}{r}\text { Standard } \\
\text { deviation }\end{array}$ & Minimum & Maximum \\
\hline Variables & 35.77 & 28.56 & 3.29 & 100 \\
Price index of capital & 52.29 & 34.15 & 10.13 & 104.36 \\
Price index of labour & 55.85 & 34.74 & 10.7 & 109.24 \\
Price index of material inputs & 60.11 & 30.34 & 18.6 & 101.11 \\
Quantity index of capital & 84.44 & 20.75 & 44.72 & 121.09 \\
Quantity index of labour & 101.51 & 10.97 & 71.49 & 122.07 \\
Quantity index of energy & 86.4 & 16.93 & 52.86 & 118.28 \\
Quantity index of material inputs & 60.97 & 20.66 & 27.06 & 100 \\
Share of capital in total cost & 9.03 & 2.97 & 1.06 & 14.14 \\
Share of labour in total cost & 20.16 & 2.52 & 15.76 & 26.06 \\
Share of energy in total cost & 7.81 & 1.57 & 5.17 & 10.77 \\
Share of material inputs in total cost & 63 & 1.84 & 59.25 & 65.63 \\
Output & 64.08 & 19.21 & 31.06 & 100 \\
\hline
\end{tabular}

Table 2: Summary statistics for the Cement industry: 1961-2003

\begin{tabular}{lrrrr}
\hline & Mean & $\begin{array}{r}\text { Standard } \\
\text { deviation }\end{array}$ & Minimum & Maximum \\
Variables & 37.29 & 29.13 & 7.92 & 105.61 \\
\hline Price index of capital & 51.3 & 30.81 & 10.3 & 100.71 \\
Price index of labour & 46.81 & 33.2 & 6.9 & 106.72 \\
Price index of energy & 57.2 & 31.25 & 16.37 & 100 \\
Price index of material inputs & 96.78 & 15.37 & 68.76 & 127.49 \\
Quantity index of capital & 82.92 & 11.11 & 56.36 & 110.29 \\
Quantity index of labour & 110.56 & 26.27 & 74.98 & 187.4 \\
Quantity index of energy & 59.43 & 16.16 & 28.65 & 105.96 \\
Quantity index of material inputs & 17.54 & 3.17 & 9.51 & 22.57 \\
Share of capital in total cost & 24.38 & 1.54 & 21.59 & 28.17 \\
Share of labour in total cost & 6.91 & 1.18 & 5.34 & 9.26 \\
Share of energy in total cost & 51.17 & 2.39 & 46.82 & 56.93 \\
Share of material inputs in total cost & 65.99 & 15.2 & 32.91 & 103.81 \\
Output index & 2579 & 1783 & 335 & 6751 \\
Total cost index & & & & \\
\hline
\end{tabular}


Table 3. Estimated coefficients of Translog input cost shares for the Metal and Cement industries

\begin{tabular}{|c|c|c|c|c|}
\hline \multirow[t]{2}{*}{ Coefficients } & \multicolumn{2}{|c|}{ Metal industry } & \multicolumn{2}{|c|}{ Cement Industry } \\
\hline & Estimates & $\begin{array}{r}\text { Standard } \\
\text { errors }\end{array}$ & Estimates & $\begin{array}{r}\text { Standard } \\
\text { errors }\end{array}$ \\
\hline \multicolumn{5}{|l|}{ Capital share equation } \\
\hline$w_{K}$ & 0.0440 & 0.002 & 0.0925 & 0.006 \\
\hline$w_{L}$ & -0.0215 & 0.002 & -0.0394 & 0.004 \\
\hline $\mathrm{w}_{\mathrm{E}}$ & -0.0057 & 0.002 & -0.0115 & 0.004 \\
\hline $\mathrm{T}$ & 0.0005 & 0.000 & -0.0011 & 0.000 \\
\hline Constant & 0.1029 & 0.004 & 0.2341 & 0.007 \\
\hline $\mathrm{R}^{2}$ & 0.8851 & & 0.8860 & \\
\hline \multicolumn{5}{|l|}{ Labour share equation } \\
\hline $\mathrm{w}_{\mathrm{K}}$ & -0.0215 & 0.002 & -0.0394 & 0.004 \\
\hline $\mathrm{w}_{\mathrm{L}}$ & 0.1172 & 0.013 & 0.1072 & 0.014 \\
\hline $\mathrm{w}_{\mathrm{E}}$ & 0.0070 & 0.006 & -0.0309 & 0.006 \\
\hline $\mathrm{T}$ & -0.0035 & 0.000 & -0.0001 & 0.000 \\
\hline Constant & 0.2838 & 0.009 & 0.2292 & 0.007 \\
\hline $\mathrm{R}^{2}$ & 0.9228 & & 0.8091 & \\
\hline \multicolumn{5}{|l|}{ Energy share equation } \\
\hline $\mathrm{w}_{\mathrm{K}}$ & -0.0057 & 0.002 & -0.0115 & 0.004 \\
\hline$w_{L}$ & 0.0069 & 0.006 & -0.0309 & 0.006 \\
\hline $\mathrm{w}_{\mathrm{E}}$ & 0.0522 & 0.006 & 0.0444 & 0.006 \\
\hline $\mathrm{T}$ & -0.0054 & 0.000 & -0.0008 & 0.000 \\
\hline Constant & 0.0972 & 0.006 & 0.0903 & 0.007 \\
\hline $\mathrm{R}^{2}$ & 0.7776 & & 0.6230 & \\
\hline \multicolumn{5}{|l|}{ Test of the overall significance } \\
\hline & 235.30 & & 204.60 & \\
\hline P-value & 0.0000 & & 0.0000 & \\
\hline
\end{tabular}

Table 4. Estimated coefficients of SGM input equations for the Metal and Cement industries

\begin{tabular}{|c|c|c|c|c|}
\hline \multirow[t]{2}{*}{ Coefficients } & \multicolumn{2}{|c|}{ Metal industry } & \multicolumn{2}{|c|}{ Cement industry } \\
\hline & Coefficients & $\begin{array}{r}\text { Standard } \\
\text { errors }\end{array}$ & Coefficients & $\begin{array}{r}\text { Standard } \\
\text { errors }\end{array}$ \\
\hline$a_{\mathrm{KK}}$ & 6.899 & 0.701 & 8.343 & 0.900 \\
\hline$a_{K L}$ & -3.237 & 1.183 & -2.109 & 2.737 \\
\hline$a_{\mathrm{KE}}$ & -8.113 & 1.882 & -10.431 & 1.558 \\
\hline$a_{L L}$ & -9.366 & 1.015 & -8.099 & 2.181 \\
\hline$a_{L E}$ & 8.755 & 0.971 & 3.321 & 5.237 \\
\hline$a_{\mathrm{EE}}$ & 0.000 & 3.593 & 0.000 & 7.388 \\
\hline $\mathrm{b}_{\mathrm{Kt}}$ & -0.008 & 0.170 & -0.024 & 0.002 \\
\hline $\mathrm{b}_{\mathrm{KK}}$ & 1.426 & 0.384 & 1.943 & 0.043 \\
\hline $\mathrm{b}_{\mathrm{Lt}}$ & -0.029 & 0.158 & -0.011 & 0.002 \\
\hline$b_{\mathrm{LL}}$ & 2.378 & 0.376 & 1.554 & 0.029 \\
\hline$b_{E t}$ & -0.012 & 0.242 & -0.034 & 0.002 \\
\hline$b_{\mathrm{EE}}$ & 1.760 & 0.607 & 2.592 & 0.045 \\
\hline $\mathrm{b}_{\mathrm{Mt}}$ & 0.001 & 0.890 & 0.000 & 0.001 \\
\hline$b_{M M}$ & 0.877 & 0.122 & 0.789 & 0.032 \\
\hline \multicolumn{5}{|l|}{$\mathrm{R}^{2}$ values } \\
\hline Capital equation & 0.796 & & 0.8165 & \\
\hline Labour equation & 0.9135 & & 0.7367 & \\
\hline Energy equation & 0.4251 & & 0.9241 & \\
\hline Material equation & 0.6169 & & 0.1156 & \\
\hline \multicolumn{5}{|l|}{ Residual variances } \\
\hline Capital equation & 0.0151 & & 0.0178 & \\
\hline Labour equation & 0.0146 & & 0.0072 & \\
\hline Energy equation & 0.0385 & & 0.0203 & \\
\hline Material equation & 0.0014 & & 0.0071 & \\
\hline Log likelihood & 219.7 & & 163.1 & \\
\hline
\end{tabular}


Table 5: Point estimates of Morishima and price elasticities in Translog and SGM specifications for the Metal industry

\begin{tabular}{l|r|r|r|r}
\hline \multirow{2}{*}{} & \multicolumn{2}{|c|}{ Morishima } & \multicolumn{2}{c}{ Price elasticities } \\
\cline { 2 - 5 } & Translog & SGM & Translog & SGM \\
\hline KK & & & -0.37 & -0.09 \\
KL & 0.14 & 0.19 & -0.07 & -0.01 \\
KE & 0.36 & 0.54 & 0.02 & 0.19 \\
KM & 0.52 & 0.00 & 0.41 & -0.09 \\
LK & 0.34 & 0.09 & -0.03 & 0.00 \\
LL & & & -0.21 & -0.19 \\
LE & 0.47 & 0.54 & 0.13 & 0.19 \\
LM & 0.24 & 0.10 & 0.13 & 0.01 \\
EK & 0.39 & 0.17 & 0.02 & 0.08 \\
EL & 0.49 & 0.39 & 0.28 & 0.20 \\
EE & & & -0.34 & -0.35 \\
EM & 0.16 & 0.17 & 0.05 & 0.07 \\
MK & 0.42 & 0.00 & 0.05 & -0.09 \\
ML & 0.25 & 0.21 & 0.04 & 0.01 \\
ME & 0.35 & 0.52 & 0.01 & 0.17 \\
MM & & & -0.11 & -0.09 \\
\hline
\end{tabular}

Table 6: Point estimates of Morishima and price elasticities in Translog and SGM specifications for the Cement industry

\begin{tabular}{l|r|r|r|r}
\hline \multirow{2}{*}{} & \multicolumn{2}{|c|}{ Morishima elasticities } & \multicolumn{2}{c}{ Price elasticities } \\
\cline { 2 - 5 } & Translog & SGM & Translog & SGM \\
\hline KK & & & -0.18 & -0.12 \\
KL & 0.29 & 0.14 & -0.03 & 0.00 \\
KE & 0.39 & 0.37 & 0.00 & 0.20 \\
KM & 0.55 & 0.05 & 0.22 & -0.08 \\
LK & 0.16 & 0.12 & -0.02 & 0.00 \\
LL & & & -0.33 & -0.15 \\
LE & 0.36 & 0.26 & -0.04 & 0.09 \\
LM & 0.71 & 0.19 & 0.38 & 0.06 \\
EK & 0.18 & 0.20 & 0.00 & 0.08 \\
EL & 0.22 & 0.20 & -0.11 & 0.05 \\
EE & & & -0.39 & -0.17 \\
EM & 0.84 & 0.17 & 0.51 & 0.03 \\
MK & 0.24 & 0.00 & 0.06 & -0.12 \\
ML & 0.51 & 0.27 & 0.19 & 0.12 \\
ME & 0.48 & 0.30 & 0.08 & 0.13 \\
MM & & & -0.33 & -0.13 \\
\hline
\end{tabular}


Table 7: Confidence intervals for Morishima elasticities of substitution for the Metal industry Translog specification

\begin{tabular}{|c|c|c|c|c|c|}
\hline & \multirow{2}{*}{$\begin{array}{l}\text { Point } \\
\text { estimates }\end{array}$} & \multicolumn{2}{|c|}{$\begin{array}{r}95 \% \text { single-bootstrap } \\
\text { confidence interval }\end{array}$} & \multicolumn{2}{|c|}{$\begin{array}{l}95 \% \text { dual-bootstrap } \\
\text { confidence interval }\end{array}$} \\
\hline & & Lower bound & Upper bound & Lower bound & Upper bound \\
\hline KL & 0.14 & -0.01 & 0.28 & -0.02 & 0.30 \\
\hline KE & 0.36 & 0.26 & 0.46 & 0.25 & 0.46 \\
\hline KM & 0.52 & 0.37 & 0.67 & 0.37 & 0.68 \\
\hline LK & 0.34 & 0.27 & 0.42 & 0.26 & 0.42 \\
\hline LE & 0.47 & 0.35 & 0.58 & 0.34 & 0.58 \\
\hline LM & 0.24 & 0.00 & 0.45 & -0.03 & 0.44 \\
\hline EK & 0.39 & 0.29 & 0.48 & 0.29 & 0.49 \\
\hline EL & 0.49 & 0.26 & 0.68 & 0.26 & 0.72 \\
\hline EM & 0.16 & -0.10 & 0.43 & -0.12 & 0.47 \\
\hline MK & 0.42 & 0.35 & 0.51 & 0.34 & 0.52 \\
\hline$M L$ & 0.25 & 0.05 & 0.44 & 0.04 & 0.47 \\
\hline ME & 0.35 & 0.21 & 0.49 & 0.20 & 0.50 \\
\hline
\end{tabular}

Table 8: Confidence intervals for Morishima elasticities of substitution for the Metal industry SGM specification

\begin{tabular}{l|c|r|r|r|r}
\hline & \multirow{2}{*}{ Estimates } & \multicolumn{2}{|c|}{$95 \%$ single-bootstrap } & \multicolumn{2}{|c}{$95 \%$ dual-bootstrap } \\
\cline { 3 - 6 } & & Lower bound & Upper bound & Lower bound & Upper bound \\
& 0.19 & 0.13 & 0.26 & 0.13 & 0.25 \\
\hline KL & 0.54 & 0.34 & 0.66 & 0.39 & 0.68 \\
KE & 0.00 & -0.01 & 0.26 & 0.00 & 0.29 \\
KM & 0.09 & 0.06 & 0.11 & 0.07 & 0.11 \\
LK & 0.54 & 0.38 & 0.67 & 0.27 & 0.51 \\
LE & 0.10 & 0.05 & 0.32 & 0.03 & 0.14 \\
LM & 0.17 & 0.11 & 0.21 & 0.13 & 0.21 \\
EK & 0.39 & 0.28 & 0.50 & 0.30 & 0.49 \\
EL & 0.17 & 0.12 & 0.36 & 0.10 & 0.22 \\
EM & 0.00 & -0.01 & 0.08 & -0.02 & 0.05 \\
MK & 0.21 & 0.13 & 0.34 & 0.09 & 0.25 \\
ML & 0.52 & 0.36 & 0.67 & 0.40 & 0.66 \\
ME & & & & &
\end{tabular}


Table 9: Confidence intervals for Morishima elasticities of substitution for the Cement industry Translog specification

\begin{tabular}{|c|c|c|c|c|c|}
\hline & \multirow{2}{*}{ Estimates } & \multicolumn{2}{|c|}{$\begin{array}{r}95 \% \text { single-bootstrap } \\
\text { confidence interval }\end{array}$} & \multicolumn{2}{|c|}{$\begin{array}{r}95 \% \text { dual-bootstrap } \\
\text { confidence interval }\end{array}$} \\
\hline & & Lower bound & Upper bound & Lower bound & Upper bound \\
\hline $\mathrm{KL}$ & 0.29 & 0.17 & 0.42 & 0.16 & 0.43 \\
\hline KE & 0.39 & 0.28 & 0.51 & 0.28 & 0.51 \\
\hline KM & 0.55 & 0.37 & 0.73 & 0.36 & 0.74 \\
\hline LK & 0.16 & 0.04 & 0.27 & 0.04 & 0.27 \\
\hline LE & 0.36 & 0.19 & 0.51 & 0.18 & 0.52 \\
\hline LM & 0.71 & 0.54 & 0.88 & 0.54 & 0.89 \\
\hline EK & 0.18 & 0.08 & 0.27 & 0.08 & 0.29 \\
\hline EL & 0.22 & 0.01 & 0.43 & -0.01 & 0.46 \\
\hline EM & 0.84 & 0.59 & 1.08 & 0.58 & 1.10 \\
\hline MK & 0.24 & 0.10 & 0.36 & 0.09 & 0.38 \\
\hline $\mathrm{ML}$ & 0.51 & 0.34 & 0.67 & 0.34 & 0.68 \\
\hline $\mathrm{ME}$ & 0.48 & 0.32 & 0.63 & 0.32 & 0.64 \\
\hline
\end{tabular}

Table 10: Confidence intervals for Morishima elasticities of substitution for the Cement industry SGM specification

\begin{tabular}{l|c|r|r|r|r}
\hline & & \multicolumn{2}{|c|}{$95 \%$ single-bootstrap } & \multicolumn{2}{|c}{$95 \%$ dual-bootstrap } \\
\cline { 3 - 6 } & Estimates & Lower bound & Upper bound & Lower bound & Upper bound \\
& & & & & \\
\hline KL & 0.14 & 0.01 & 0.36 & 0.00 & 0.28 \\
KE & 0.37 & 0.20 & 0.52 & 0.20 & 0.47 \\
KM & 0.05 & -0.01 & 0.44 & 0.00 & 0.39 \\
LK & 0.12 & 0.06 & 0.19 & 0.07 & 0.20 \\
LE & 0.26 & 0.08 & 0.53 & 0.06 & 0.33 \\
LM & 0.19 & 0.04 & 0.56 & 0.01 & 0.32 \\
EK & 0.20 & 0.15 & 0.25 & 0.15 & 0.23 \\
EL & 0.20 & 0.05 & 0.45 & 0.03 & 0.34 \\
EM & 0.17 & 0.08 & 0.50 & 0.08 & 0.31 \\
MK & 0.00 & -0.04 & 0.14 & -0.04 & 0.12 \\
ML & 0.27 & 0.02 & 0.58 & -0.01 & 0.35 \\
ME & 0.30 & 0.12 & 0.63 & 0.11 & 0.47 \\
\hline
\end{tabular}


Table 11: Confidence intervals for price elasticities for the Metal industry Translog specification

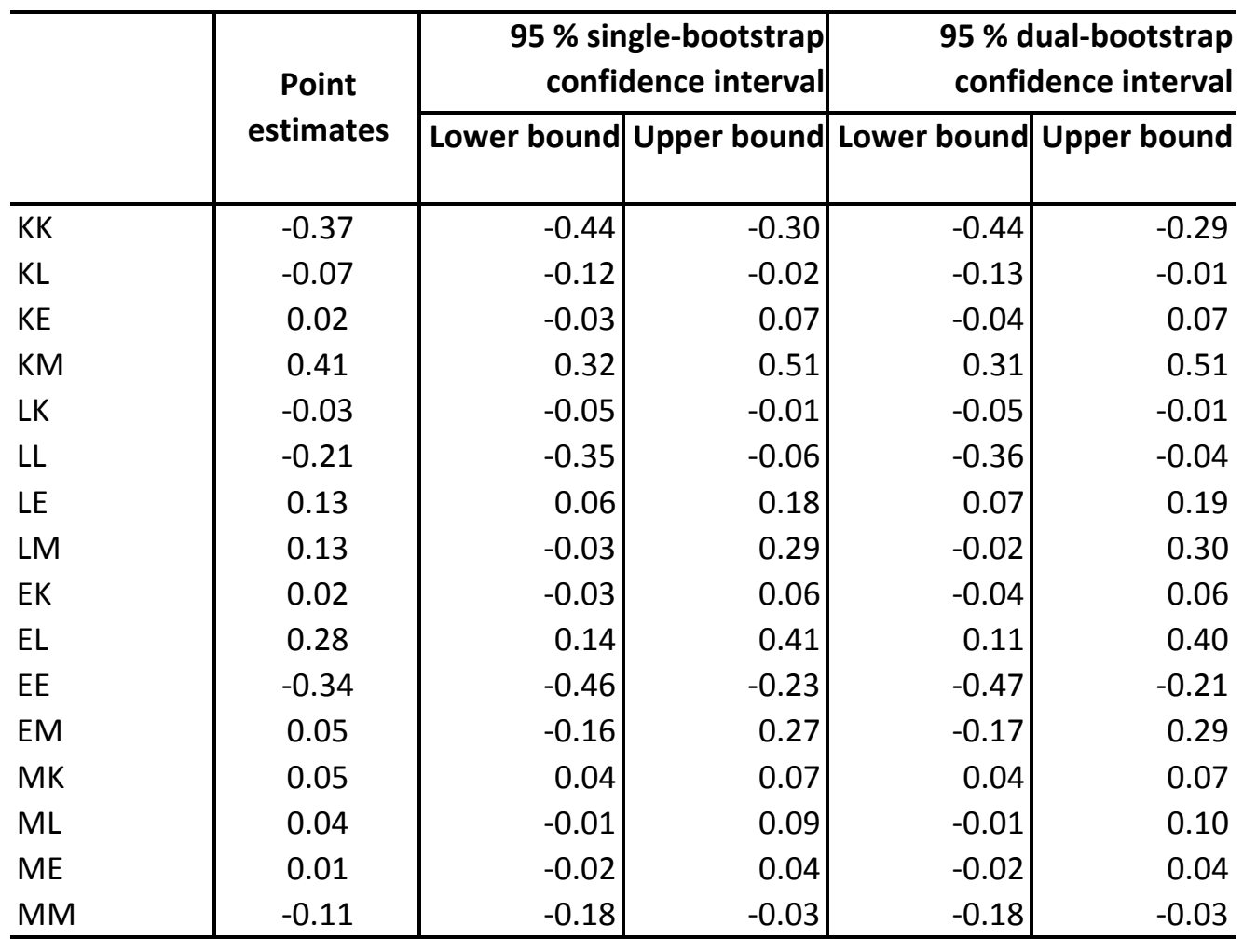

Table 12: Confidence intervals for price elasticities for the Metal industry SGM specification

\begin{tabular}{l|c|rr|rr}
\hline & & 95 \% single-bootstrap & \multicolumn{2}{|c}{ 95 \% dual-bootstrap } \\
\cline { 3 - 6 } & Estimates & Lower bound Upper bound & Lower bound Upper bound \\
\hline KK & -0.09 & -0.11 & -0.07 & -0.11 & -0.07 \\
KL & -0.01 & -0.04 & 0.03 & -0.04 & 0.03 \\
KE & 0.19 & 0.09 & 0.24 & 0.08 & 0.22 \\
KM & -0.09 & -0.11 & -0.01 & -0.09 & 0.03 \\
LK & 0.00 & -0.02 & 0.01 & -0.02 & 0.01 \\
LL & -0.19 & -0.25 & -0.15 & -0.24 & -0.15 \\
LE & 0.19 & 0.14 & 0.23 & 0.16 & 0.25 \\
LM & 0.01 & -0.02 & 0.05 & 0.00 & 0.06 \\
EK & 0.08 & 0.03 & 0.10 & 0.02 & 0.08 \\
EL & 0.20 & 0.13 & 0.25 & 0.12 & 0.20 \\
EE & -0.35 & -0.44 & -0.24 & -0.42 & -0.23 \\
EM & 0.07 & 0.05 & 0.11 & 0.05 & 0.11 \\
MK & -0.09 & -0.11 & -0.01 & -0.12 & -0.04 \\
ML & 0.01 & -0.05 & 0.12 & -0.07 & 0.08 \\
ME & 0.17 & 0.11 & 0.24 & 0.11 & 0.23 \\
MM & -0.09 & -0.28 & -0.06 & -0.27 & -0.07 \\
\hline
\end{tabular}


Table 13: Confidence intervals for price elasticities for the Cement industry Translog specification

\begin{tabular}{|c|c|c|c|c|c|}
\hline & \multirow{2}{*}{ Estimates } & \multicolumn{2}{|c|}{$\begin{array}{r}95 \% \text { single-bootstrap } \\
\text { confidence interval }\end{array}$} & \multicolumn{2}{|c|}{$\begin{array}{l}95 \% \text { dual-bootstrap } \\
\text { confidence interval }\end{array}$} \\
\hline & & Lower bound & Upper bound & Lower bound & Upper bound \\
\hline KK & -0.18 & -0.27 & -0.07 & -0.28 & -0.07 \\
\hline KL & -0.03 & -0.09 & 0.02 & -0.11 & 0.02 \\
\hline KE & 0.00 & -0.05 & 0.06 & -0.06 & 0.06 \\
\hline KM & 0.22 & 0.10 & 0.33 & 0.09 & 0.34 \\
\hline LK & -0.02 & -0.05 & 0.01 & -0.05 & 0.01 \\
\hline LL & -0.33 & -0.44 & -0.21 & -0.44 & -0.20 \\
\hline $\mathrm{LE}$ & -0.04 & -0.08 & 0.01 & -0.09 & 0.01 \\
\hline LM & 0.38 & 0.27 & 0.49 & 0.26 & 0.49 \\
\hline EK & 0.00 & -0.08 & 0.09 & -0.08 & 0.09 \\
\hline EL & -0.11 & -0.25 & 0.03 & -0.24 & 0.04 \\
\hline $\mathrm{EE}$ & -0.39 & -0.53 & -0.26 & -0.53 & -0.24 \\
\hline EM & 0.51 & 0.32 & 0.70 & 0.31 & 0.72 \\
\hline MK & 0.06 & 0.03 & 0.09 & 0.02 & 0.09 \\
\hline$M L$ & 0.19 & 0.13 & 0.24 & 0.13 & 0.24 \\
\hline $\mathrm{ME}$ & 0.08 & 0.05 & 0.11 & 0.05 & 0.11 \\
\hline MM & -0.33 & -0.41 & -0.26 & -0.41 & -0.25 \\
\hline
\end{tabular}

Table 14: Confidence intervals for price elasticities for the Cement industry SGM specification

\begin{tabular}{l|c|r|r|r|r}
\hline & & \multicolumn{2}{|c|}{$95 \%$ single-bootstrap } & \multicolumn{2}{|c}{ 95 \% dual-bootstrap } \\
\cline { 3 - 6 } & Estimates & Lower bound & Upper bound & Lower bound & Upper bound \\
\hline KK & -0.12 & -0.16 & -0.09 & -0.15 & -0.09 \\
KL & 0.00 & -0.06 & 0.06 & -0.03 & 0.07 \\
KE & 0.20 & 0.10 & 0.25 & 0.14 & 0.25 \\
KM & -0.08 & -0.10 & 0.01 & -0.08 & 0.02 \\
LK & 0.00 & -0.05 & 0.05 & -0.04 & 0.04 \\
LL & -0.15 & -0.32 & -0.04 & -0.31 & -0.07 \\
LE & 0.09 & -0.01 & 0.25 & 0.05 & 0.27 \\
LM & 0.06 & -0.04 & 0.16 & 0.01 & 0.17 \\
EK & 0.08 & 0.04 & 0.11 & 0.02 & 0.09 \\
EL & 0.05 & -0.01 & 0.14 & -0.02 & 0.08 \\
EE & -0.17 & -0.30 & -0.08 & -0.30 & -0.11 \\
EM & 0.03 & 0.00 & 0.10 & 0.01 & 0.07 \\
MK & -0.12 & -0.16 & 0.01 & -0.15 & -0.01 \\
ML & 0.12 & -0.08 & 0.33 & -0.04 & 0.30 \\
ME & 0.13 & 0.02 & 0.35 & 0.00 & 0.23 \\
MM & -0.13 & -0.44 & -0.05 & -0.48 & -0.09 \\
\hline
\end{tabular}


Fig 1: Evolution of own-price elasticities for inputs in the Metal Industry Translog specification

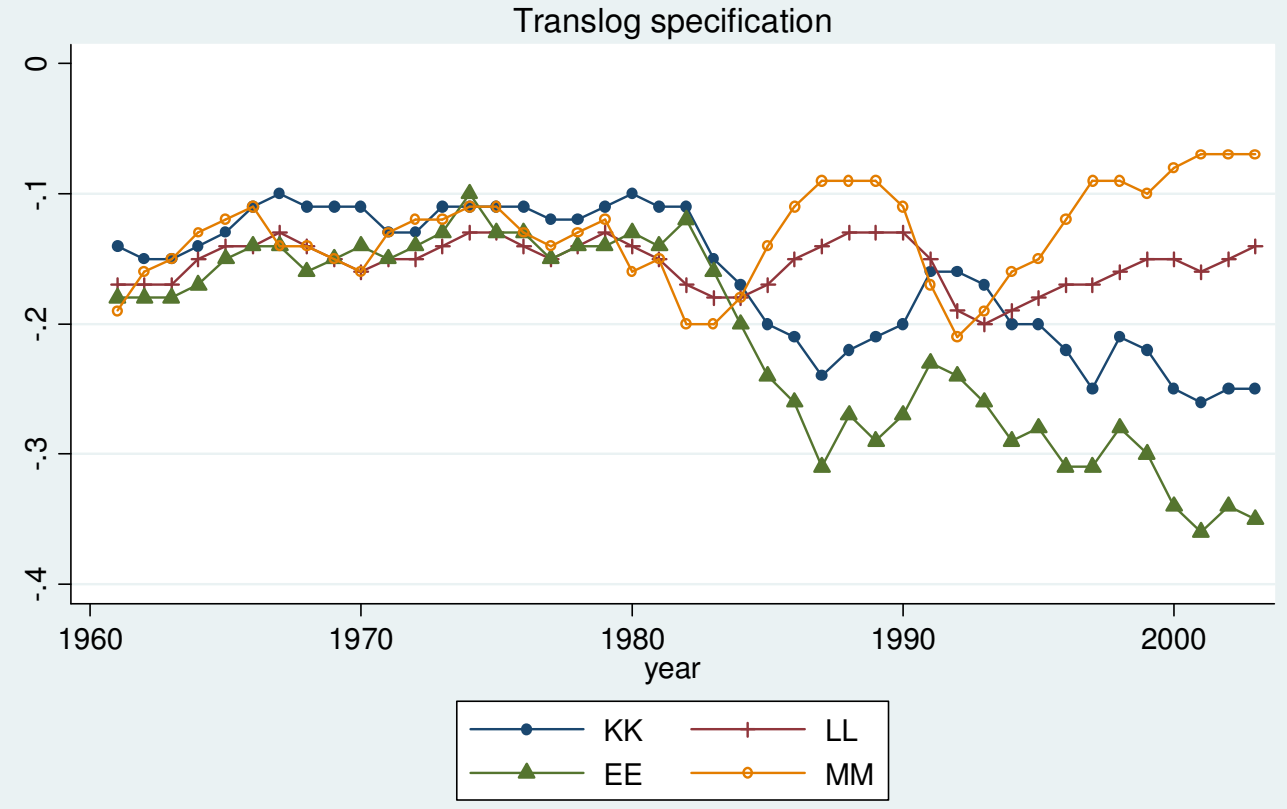

Source: Authors' calculations

Fig 3: Evolution of Morishima elasticities in the Metal Industry Translog specification

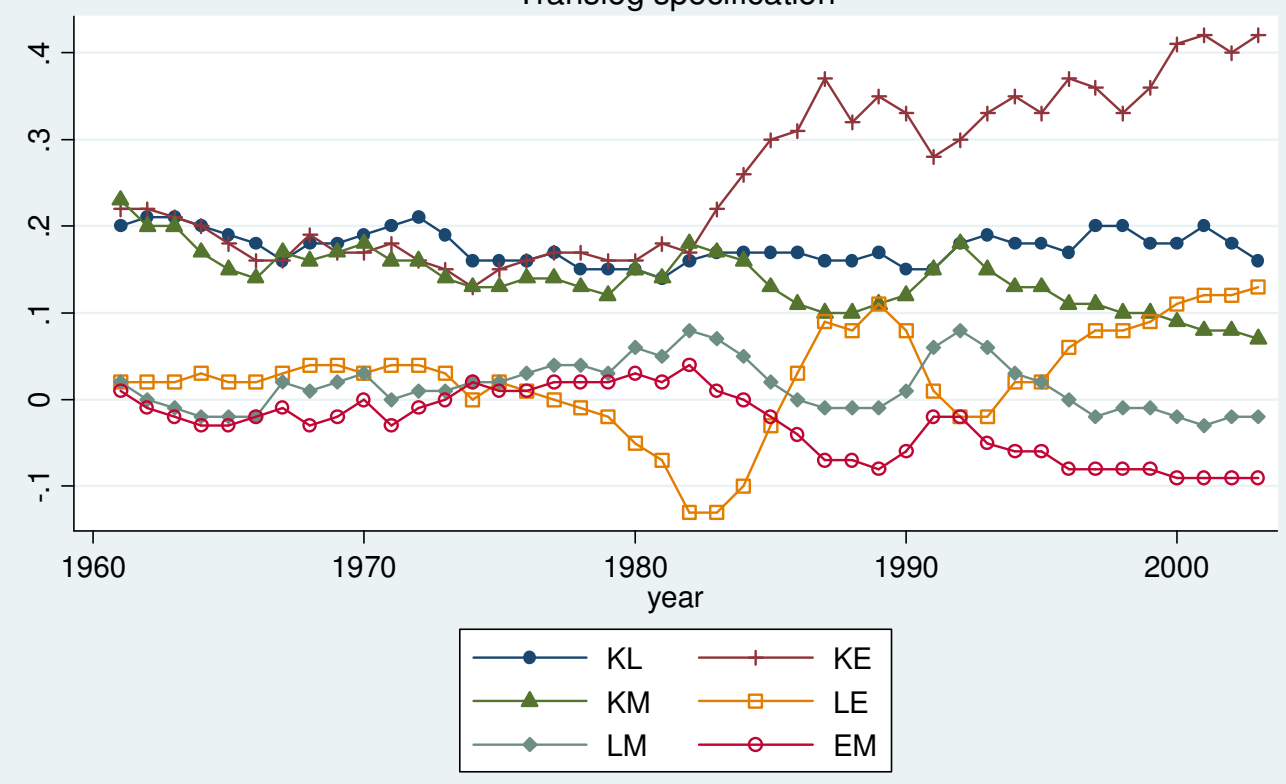

Fig 2: Evolution of own-price elasticities for inputs in the Cement Industry Translog specification

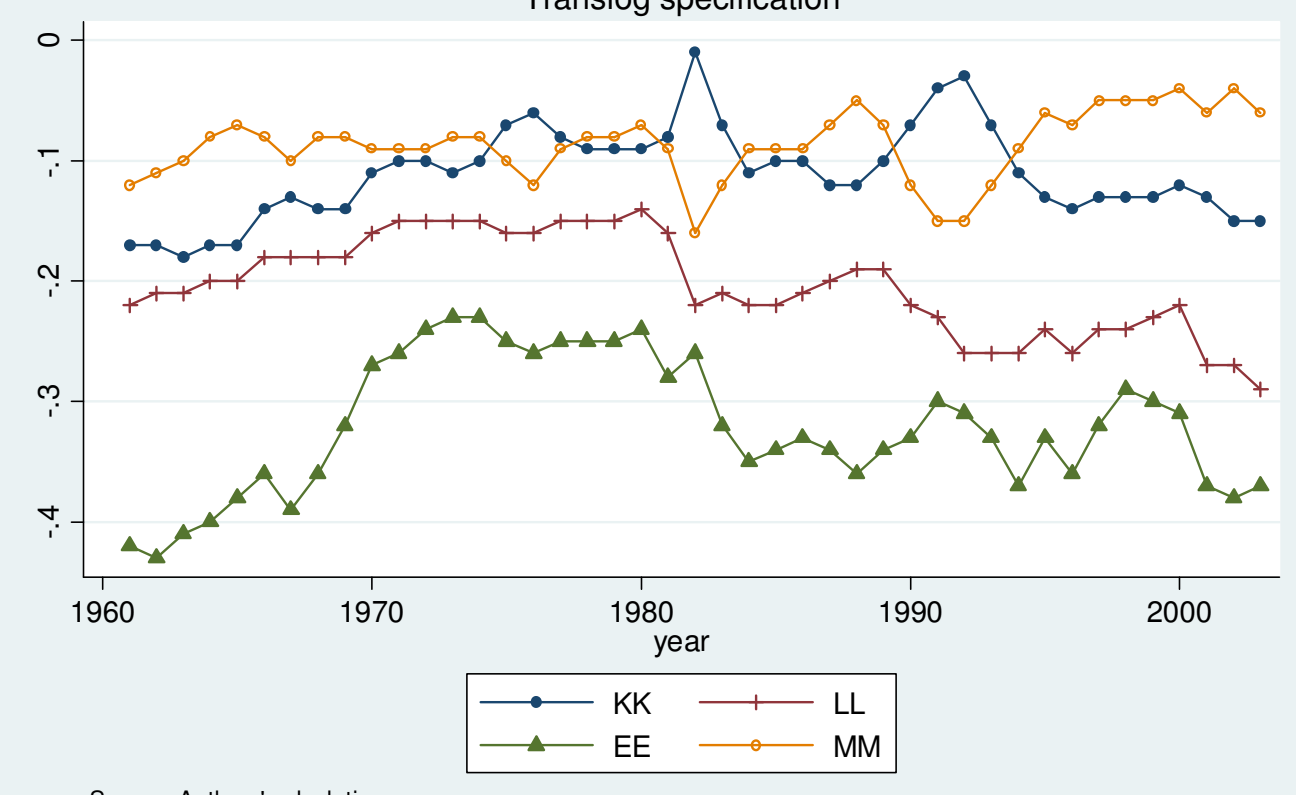

Source: Authors' calculations

Fig 4: Evolution of Morishima elasticities in the Cement Industry Translog specification

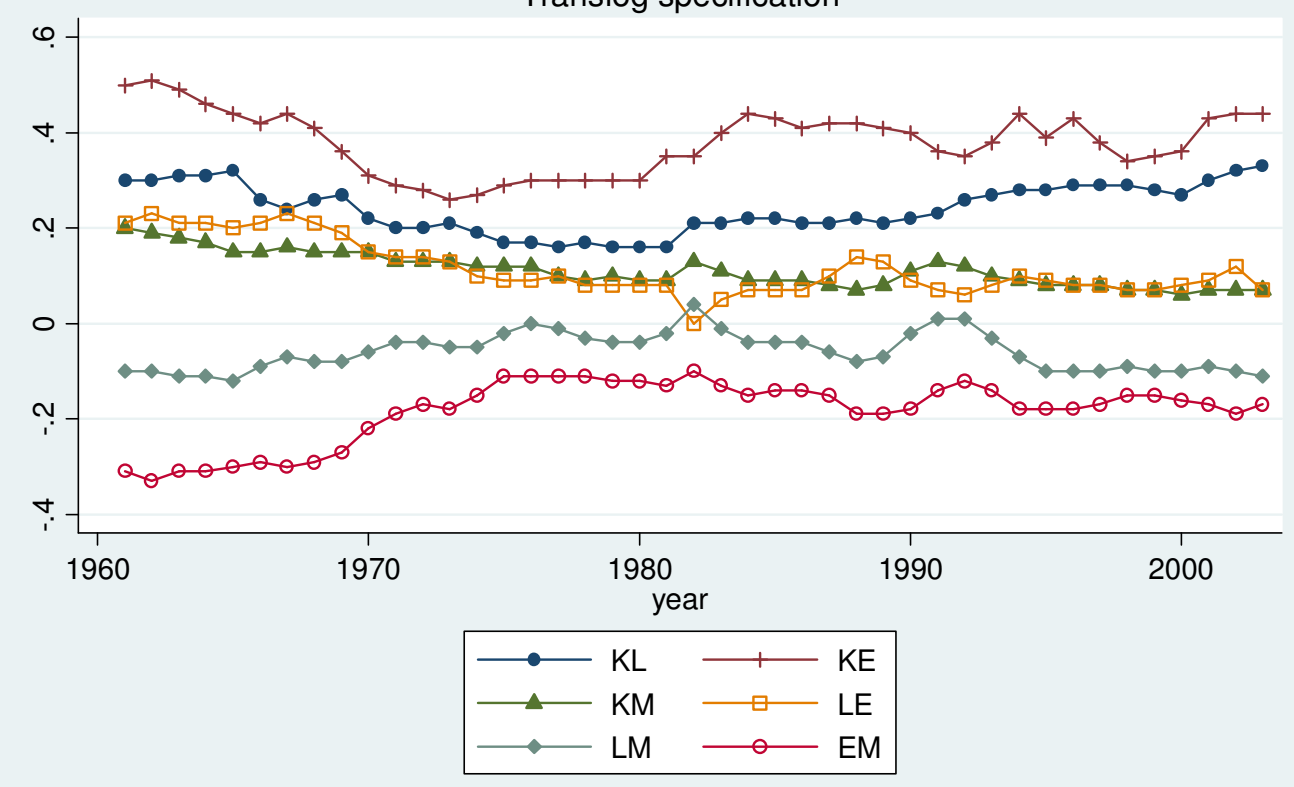

Source: Authors' calculations 